\title{
A CASA DOS EXPOSTOS
}

Moacyr Flores*

A Santa Casa de Misericórdia de Porto Alegre desempenha, desde o iń́cio de seu funcionamento, em 1826, destacado papel social atendendo doentes pobres, presos indigentes, alienados, dando assistência aos condenados à forca, fazendo enterro dos desamparados, criando e educando os expostos. Estas funçōes variam no tempo de acordo com as mudanças políticosociais brasileiras.

O presente trabalho apresenta dados de uma pesquisa, ainda em andamento, sobre a Casa dos Expostos da Santa Casa de Misericórdia de Porto Alegre, coletados em relatórios dos presidentes da província, relatórios do provedor da Santa Casa, livros de matrícula, livros de registro, livros de óbito. Os dados estão sendo fichados para mais tarde serem quantificados, analisados e interpretados.

O objetivo do trabalho é determinar as modificaçōes ocorridas nas tradiçб̄es religiosas, principalmente na caridade, através das relaçōes existentes entre a Santa Casa e os expostos.

Exposto ou enjeitado era a criança abandonada pelos genitores e criada pela caridade pública. Desde o período colonial que a manutenção dos expostos competia à Câmara Municipal que, através de verba especial, contratava mulheres, chamadas de criadeiras, para cuidarem das crianças. A lei provincial no 9, de 21.11.1837, consignou a minguada quantia de 12 contos de réis para a criação dos expostos e curativo dos presos pobres. A mesma lei estabeleceu a Casa da Roda em um dos prédios da Santa Casa de Misericórdia, para cuidar dos enjeitados. Num dos muros abriram um buraco, colocando do lado de dentro a roda de madeira, em forma de tambor com uma pequena abertura, que girava em torno de um eixo. Altas horas da noite, ocultando-se nas sombras, alguém deslisava encostado ao muro até chegar à roda. Introduzia a infeliz criança na abertura do muro, colocando-a na roda. Girava a roda, tocava a sineta e fugia correndo, a fim de ocultar sua identidade.

A porteira, que dormia junto à roda, recolhia a criança imediatamente, entregando-a à regente com o enxoval ou qualquer objeto que trouxesse 
com ela. A regente examinava o exposto, prestando socorro imediato as enfermas e maltratadas. Colocava no pescoço do enjeitado uma pequena chapa numerada, de acordo com o livro de matrículas. (Regimento Casa dos Expostos, art. 28 a 29)

No livro de registro anotava o número de entrada, sexo, cor, idade que mostrasse ter, estado de saúde, o dia, a hora, o mês e o ano que foi achada na roda. Apontava também o enxoval ou roupa. qualquer papel escrito, medalha ou sinal, pelos quais se poderia reconhecer, se algum dia viesse ser procurada. Depois a regente designava a ama-de-leite e a ama-de-criação, encarregadas de seu tratamento. No outro dia o médico examinava o enjeitado, anotando todos os sinais e marcas, vacinando se fosse necessário. Depois o Irmao Mordomo faria batizar o inocente para que nao morresse pagão. No mesmo dia a criança era dada a uma criadeira, que em troca de pagamento, cuidaria do menino até os 7 anos e da menina até os 8 anos, devolvendo para a Casa da Roda.

A Casa dos Expostos começou a funcionar em 1838, mas só em 12.6.1842 teve seu regimento elaborado por Saturnino de Souza Oliveira, que era provedor e também presidente da província.

A administração da Casa dos Expostos era confiada a 4 irmãos da Santa Casa, com as funçбes de mordomo, escrivăo, tesoureiro e procurador, aplicando para sua manutenção os rendimentos de bens doados pelo governo e por particulares. Estes administradores eram nomeados anualmente pela Mesa da Santa Casa, depois de eleitos em escrutínio secreto.

$\mathrm{O}$ irmão mordomo desempenhava tarefas administrativas, econômicas e fiscais, sendo responsável pela limpeza e asseio dos inocentes. Distribuía as tarefas e fiscalizava a alimentação. Zelava para que não faltasse o necessário para o tratamento do pessoal do estabelecimento e para que os gêneros destinados ao alimento das amas-de-leite fossem adequados e promovessem abundância de leite. $\mathrm{O}$ irmão mordomo informava sobre os requerimentos das pessoas que pretendiam adotar algum enjeitado. Cabia-lhe despedir as amas-de-leite que engravidassem, porque teriam que amamentar o próprio filho. Mensalmente deveria inspecionar as casas das criadeiras na cidade. (Regimento da Casa dos Expostos, art. 15 e 16)

O irmão escrivão era o segundo funcionário em autoridade, competindo-lhe a escrituração, contabilidade e estatística da Casa dos Expostos. (Regimento da Casa dos Expostos, art. 17 e 18)

$\mathrm{O}$ irmao tesoureiro recebia as doaçøes da Santa Casa, pagando os funcionários, que não podiam ter os vencimentos atrasados, as despesas com gêneros alimentícios e roupas. (Reg. Casa dos Expostos, art. 19 a 21)

Competia ao irmão procurador comprar todos os gêneros para o sustento da Casa dos Expostos. 
Além desses funcionários eleitos existiam empregados contratados como o médico ou cirurgiao, as amas-de-leite, as amas-de-criação, serventes internas e um servente externo.

De acordo com o regimento, a regente seria escolhida por ser uma muther honesta, prudente, de avançada idade, que soubesse ler e escrever. Recebia ordenado com direito à cama, alimento e roupa lavada. A regente advertia e repreendia os demais empregados, seus subordinados, sempre que deixassem de cumprir com suas obrigaçб̄es, ou tivessem conduta irregular. Cuidava para que as crianças fossem lavadas em horas regulares e se conservassem sempre limpas com roupas asseadas e enxutas. Assistia pessoalmente ao refeitório, obrigando a todos guardarem silêncio e ordem, dando graças a Deus no fim de cada refeição.

A porteira deveria ser também de avançada idade, competindo-lhe conservar fechadas as portas da Casa dos Expostos desde o pôr-do-sol até o seu nascimento e desde o meio-dia até às duas horas. Quando a sineta da roda tocasse, a porteira tinha que retirar diligentemente a criança. Examinava todos os volumes que os demais empregados portassem na entrada ou na safda.

As amas-de-criaçao seriam selecionadas da classe das expostas, de preferência as maiores de idade, que assim ajudariam a cuidar dos menores, auxiliando as amas-de-leite. As amas-de-leite eram pagas para amamentarem os lactentes, que permaneciam na Casa da Roda, evitando-se que 2 crianças mamassem na mesma ama.

Permaneciam na Casa dos Expostos de 10 a 15 crianças, por estarem doentes ou aguardarem vaga no asilo S. Leopoldina ou no Arsenal. A maioria, quase uma centena de enjeitados, permaneciam com as criadeiras contratadas.

O sistema de criadeiras foi considerado a melhor solução pela Câmara de Vereadores e depois pela Santa Casa. A criadeira, verdadeira profissional, cuidava em sua casa de um exposto, contratando a ama-de-leite, que poderia ser uma escrava alugada, conforme os numerosos anúncios em jornais da época. A criadeira recebia ordenado mensal até a criança completar 7 anos, sendo varđo e até 8 anos sendo fêmea. Se a criadeira ño entregasse o exposto até 3 meses depois de expirar estes prazos, ficaria responsável por sua criação gratuíta até os 12 anos, quando passaria o cargo dos Juízes de Orfãos.

De acordo com o alvará de 24.10.1814, toda a pessoa que recolhesse e criasse algum órfão, mandando-o ensinar a ler e escrever, poderia conservá-lo até os 16 anos sem pagar salários por seus serviços. A família que criasse o exposto poderia dá-lo para o serviço militar em lugar de algum filho re- 
crutado. Quem, por caridade, adotasse uma criança teria que pagar todos os gastos que a Casa dos Expostos teve para criá-la.

Os meninos, que retornassem à Casa dos Expostos com 7 anos, iriam, para o Arsenal aprender uma profissão. As meninas com 8 anos, que fossem entregues pelas criadeiras, ajudariam a cuidar dos pequenos, transformadas em amas-secas, estudariam bordado e costura, recebendo um dote quando chegassem a idade de 18 anos.

No relatório de 1868, o provedor Luis Manoel de Lima e Silva informa que, com a licença da Mesa, casou a exposta Elvira Emília Gomes com José Pereira da Fonseca, dando para seu enxoval a quantia de $320 \$ 000$ réis e mais a caderneta no banco da Província com $782 \$ 790$ réis, donativo feito pela sociedade de música Firmeza e Esperança, através de sorteio no ano de 1866. O provedor relata que na Roda existem 16 recolhidas, sendo 4 em idade de casar. Segundo sua narrativa, para qualquer exposta com dote "apareciam maridos, mas as que ño tinham jamais eram procuradas e continuam a pesar sobre a Santa Casa com avıltadas despesas que fazem com sua manutenção e vestuário". (Relatório de 1868, pág.14/15)

A lei 367 , de 4.3.1857 criou o Asilo Santa Leopoldina, instalado em 7 de setembro, para o ensino de primeiras letras, liçø̃es de costura e bordados para as expostas de mais de 8 anos e para as órfas acima de 5 anos. Com a solenidade de inauguraçao, recolheram 26 expostas no asilo, permanecendo na Casa da Roda 9 enjeitadas, sendo 8 púberes, èm idade de tomarem estado (casar), pois o estabelecimento nđo era adaptado ao recolhimento, além despesa de manutenção ser maior que a dotação de verba (Relatório de 1858, p.67)

A partir de 1868, as 16 expostas recolhidas na Casa da Roda, recebiam nos dias úteis lições de primeiras letras e liçōes de costura, aos cuidados da professora Belmira Joaquina da Rosa.

O governo da província destinava uma verba para as despesas com os presos pobres, menores do Arsenal, praças policiais doentes, criadeiras dos expostos e sustento dos menores recolhidos à Casa da Roda, sempre insuficiente para os gastos. A Santa Casa conseguia outros rendimentos, como os foros dos terrenos dos expostos, que deram, em 1868, a quantia de $156 \$ 000$ réis, havendo muitos foros remissões há mais de 14 anos. Alguns deixavam legados, como Cândido Rodrigues Pereira que deu $100 \$ 000$ réis para o dote da primeira exposta que fosse lançada à Roda, depois da hora de seu falecimento. Conforme relatório de 1878, Gabriel Alves Azambuja, tesoureiro das loterias da província e irmão da Santa Casa, solicitava aos ganhadores esmolas para os dotes das expostas.

Sendo a corrupção universal, a pia instituição da Roda dos Expostos não poderia ficar isenta deste mal irreparável. Em 1863 descobriram as fal- 
catruas do tesoureiro Amaro da Silva Velho, quando ele fugiu para o estrangeiro levando a fabulosa soma de 3:557\$639 réis, além de ter usufruído de 2:587\$119 réis, quantias desviadas com guias e conhecimentos falsos.

A Mesa da Santa Casa nomeou uma comissão formada por Leopoldino Joaquim de Freitas e Simeđo Damasceno da Silva Rosa, para apurar a extensđ̃o da defraudação.

O tesoureiro era encarregado do livro de receita e despesa, escriturado de janeiro a dezembro de cada ano. Amaro da Silva Velho adulterou as despesas, para o ano de 1862 , de 14:122\$674 réis para 16:635\$820 réis, conforme apurou a comissão, colocando outros nomes de crianças em matrículas de expostos mortos e emitindo conhecimentos em nome de outras criadeiras, sacando com estes documentos falsos a quantia de 2:513\$146 réis. $\mathrm{O}$ tesoureiro desonesto pagou 3 vezes os salários das criadeiras de outubro a novembro de 1861 , incluindo as guias dos mortos e adotados em nome de falsas criadeiras. Era o que hoje chamaríamos de criança-papel, semelhante, porém em menor escala, aos escândalos impunes do trigo-papel e da mandioca-papel.

A comissão teve dificuldades em conferir o livro de receita e despesa, não conseguindo verificar o patrimônio da Casa da Roda, ou sejam, as quantias que o tesoureiro Amaro da Silva Velho recebeu da Santa Casa, os foros e laudêmios dos terrenos da cidade que constituíam o patrimônio dos expostos, de acordo com os artigos 52 e 53 do regimento, que passaram da Câmara Municipal para a Santa Casa, em 1838, os produtos de loterias, os saldos de um ano para outro, as indenizaçбes de retiradas de enjeitados pelos parentes, os juros de apólices e outras doaçбes.

A comissão de devassa também verificou que nao existiam as tabelas das raçб̄es com despesas, para alimentaçđo dos expostos, encontrando apenas listas de gêneros com preços exorbitantes, às vezes o dobro, pagos pelo tesoureiro ladrão. Esta prática infelizmente ainda perdura nas célebres concorrências públicas, em que os preços sđo elevados a fim de cobrirem a polpuda comissđ̃o do funcionário "comprador".

Os livros de entrada dos expostos, ao cargo da regente, e os livros de matrículas, anotados pelo escrivão, também estao incompletos, sendo impossível verificar se o exposto completara a idade, ficara em poder da criadeira, fora adotado ou morrera, facilitando a emissđo de guias falsas. $\mathrm{O}$ tesoureiro mudou a seqüência de numeraçao das guias, alterando o número de matrícula 845 para 745 , a partir do ano de 1857 , quando iniciou suas atividades fraudulentas. Refazendo a seqüência antiga da numeraçao, a comissão constatou que de 1.1.1838 a 31.5.1863 entraram na Casa da Roda: 
Expostos masculinos . . . . . . . . . . . . . . . . 529

Expostos femininos . . . . . . . . . . . . . 615

Total . . . . . . . . . . . . . . . . . 1.144

Deste total de 1.144 faleceram até o ano de 1863 :

Expostos masculinos . . . . . . . . . . . . . 352

Expostos femininos . . . . . . . . . . . . 359

Total . . . . . . . . . . . . . . . 711

Conforme os dados acima, ficaram sob a responsabilidade da Casa da Roda, durante o período de 1838 a 1863 , um total de 433 expostos, que foram distribuídos da seguinte maneira:

Em poder de criadeiras . . . . . . . . . . . 271

Em poder de pessoas diversas . . . . . . . . . . . . . 74

Meninas no asilo $\mathrm{S}$. Leopoldina . . . . . . . . . . . 36

Meninos no Arsenal de Guerra . . . . . . . . . . 32

Casaram . . . . . . . . . . . . . . . 10

Na Casa da Roda . . . . . . . . . . . . . 10

Total . . . . . . . . . . . . . . . . . . . 433

O tesoureiro Amaro da Silva Velho usava seu artifício para calcular a despesa ordinária de cada exposto do sexo masculino, até completar a idade de 7 anos, supondo que o mesmo fosse recolhido na Roda no dia de nascimento e em seguida entregue à criadeira:

Salário de 18 meses a $10 \$ 000$ rs . . . . . . . . $180 \$ 000$

Dito de 5 e $1 / 2$ anos a $5 \$ 000$ rs . . . . . . . . $330 \$ 000$

Vestuário $\mathrm{p} / 7$ anos a $6 \$ 400 \mathrm{rs} \ldots \ldots \ldots \ldots \ldots 44 \$ \ldots 00$

Total . . . . . . . . . . . . . . . . . 554\$800

Do sexo feminino até completar 8 anos seria:

Salário de 18 meses a $10 \$ 000$ rs . . . . . . . . $180 \$ 000$

Dito de 6 e $1 / 2$ anos a $5 \$ 000$ rs . . . . . . . . $390 \$ 000$

Vestuário $\mathrm{p} / 8$ anos a $6 \$ 400 \mathrm{rs} \ldots \ldots \ldots \ldots . . . \ldots 51 . \ldots 200$

Total . . . . . . . . . . . . . . . . 621\$200

Manipulando estes dados e contando que restavam vivos 433 expostos, o tesoureiro apresentava uma despesa de criação de $891 \$ 215$ rs, no mesmo espaço de tempo, as subvençбes do cofre provincial a Santa Casa elevaram-se à quantia de 450:309\$516 rs.

No relatório do presidente da Província, Espiridiao de Barros Pimentel, encontramos que existiam, em 31.12.1863, o total de 289 expostos, 
sendo 132 meninos e 157 mulheres, portanto o tesoureiro Amaro da Silva Velho manipulou com 144 crianças-papel, sendo que 40 já estavam mortas e 104 eliminadas da matrícula por não terem mais direito à pensđo por terem completado a idade, ficando em poder da criadeira ou foram adotados.

Desde agosto de 1862 que o tesoureiro fazia retiradas em proveito próprio do cofre dos expostos, resta saber até que ponto o escrivão, a regente e o médico, por anotarem as matrículas, acontecimentos e óbitos, tinham conhecimento da fraude.

As infelizes crianças também sofreram em mãos das criadeiras inescrupulosas, que por suas atitudes negavam a virtude da caridade cristã. $\mathrm{O}$ irmão Vicente José de Barcelos Júnior, mordomo dos expostos em 1884, mostrava-se preocupado com a sorte dos enjeitados, criados fora do estabelecimento:

"As criadeiras que se apresentam oferecendo os seus serviços e muitas vezes empenhando-se para a obtenção dos expostos, existem em quantidade tal que são demasiadas para os filhos da Roda. O espírito da ganância, o desejo de auferir a mensalidade dada pela Santa Casa, é que as leva, na sua quase totalidade, a procurarem esse meio de vida.

Pobreš quase sempre, as criadeiras sustentam-se com o dinheiro dos enjeitados e não é raro vê-los enfesados, raquíticos, mal vestidos e famintos, porque para eles são somente os sobejos e restos de suas maes adotivas. Muitas chegam mesmo a deixá-las morrer de fome ou pelo abandono e falta de cuidados, continuando no entanto a perceber a gratificação mensal, para o que empregam os meios necessários de iludir a nossa fiscalização".

O que sempre nos impressionou durante a pesquisa, foi o fato da criança abandonada, durante a noite, ser batisada e entregue à criadeira no dia seguinte, criadeiras que moravam distantes, como as de Gravataí, Viamão e Taquari, e que não haveria tempo de avisá-las. As candidatas e criadeira deveriam permanecer junto à Santa Casa, esperando que uma criança fosse abandonada na Roda.

O relatório de 1876 informa que várias criadeiras não buscavam o pagamento. O relatório de 1884 informa que 105 crianças estavam nas maos de criadeiras, só uma estava em criação gratuita.

O mordomo Barcelos informa que quando assumiu a mordomia existiam na Casa da Roda 10 expostas, sendo 8 maiores e 2 menores.

"Foi meu primeiro empenho dar a estas expostas destino compatível com a moralidade de nossos costumes, fazendo retirá-las do estabelecimento, por entender que a manutençao delas pela Santa Casa deve cessar logo que atingirem a maioridade legal, o que facilmente consegui com o casamento de 6 das mencionadas expostas e a retirada de uma outra para a casa da família do irmao Augusto César Fernandes Eiras." 
Segundo a moralidade da época, uma mulher não poderia viver sozinha, deveria permanecer com uma família ou sob a proteção de um marido para ser respeitada pela comunidade. Das 3 que permaneceram na Roda, 2 eram menores e estavam sendo pedidas por chefes de famílias, a terceira era maior de idade, mas nao gozava de perfeito uso da razão, sendo aproveitada como porteira da Casa dos Expostos. As menores nao foram entregues para que seu pecúlio aumentasse, pois em casa de famflias seriam empregadas sem ordenado. $\mathrm{O}$ mordomo Barcelos apresentou as despesas com os 102 expostos criados fora da Roda e com os dotes das 6 que casaram, argumentando que não convém a continuação do recolhimento na Casa da Roda por causa da excessiva despesa. Critica também o sistema de entregar as crianças a criadeiras e de esperar 7 ou 8 anos até que retornem à Roda já criadas, obrigando despesas com as maes adotivas temporárias, o que seria evitado se as crianças fossem entregues a boas famflias, que poderiam educá-las até o casamento. O mordomo Barcelos analisou o sistema de criadeiras pagas, dizendo que estas crianças sao como escravos, maltrapilhos, imundos e ignorantes, ocultando em suas almas um criminoso ou um vagabundo do futuro.

Esta avaliação é uma contradiçáo com o discurso inicial do provedor, que em tudo vê a caridade crista. O mordomo Barcelos apresentou a idéia de aproveitarem os pavilhøes desocupados pela enfermaria militar, para neles funcionar uma creche, sustentada pela caridade pública, que certamente melhoraria a criação dos enjeitados, dando-lhes inclusive um pouco de afeto.

Desde 1856 a Santa Casa vinha tentando mudar o sistema de criação na Casa da Roda. A superiora e 2 irmas do Sagrado Coração de Maria estavam em Pelotas, quando o provedor, com aprovação da Mesa, mandou buscá-las na barca a vapor. Chegaram em 2.12.1856 e foram levadas em visitação à Casa da Roda. Desde que as irmas entraram no prédio, mostraram desapontamento, fazendo uma série de exigências, que, após uma reuniao, os componentes da Mesa se convenceram que seria impossível admiti-las. (Relatório de 1857, p.5)

Neste ano havia na Roda 43 crianças, com 36 recebendo aulas da professora Ana Guterres da Silva, que era pouco zelosa no cumprimento do magistério e nada assídua.

Em seu relatório de 1884 , o provedor Joaquim Pedro Salgado, ao argumentar que seria melhor substituir enfermeiros e enfermeiras por irmás de caridade, usa um discurso esteriotipado sobre a caridade crista, que em nada combina com o relatório sobre a Casa da Roda, conforme já vimos anteriormente:

"Está provado porque os fatos o demonstram, que o trabalho das enfermeiras deve ser confiados unicamente às irmas de caridade." 
"Anjos de abnegaçao, votadas ao sacrifício, tendo a caridade como única profissão; as heroinas do bem que o povo com o seu costumado bom senso denominou - irmas da caridade, elas possuem o segredo de enfermeiras e dispoem de recursos inexauríveis de meios desconhecidos, inventados pela virtude do altruísmo; e tudo, com o desprendimento e dedicação da mulher crista, dao aos doentes, emprestam aos pobres - convencidas e certas do pagamento divino. Tratando de curar o espírito abatido pela dor e o corpo vencido pela moléstia, elas sabem ao ministrar o remédio que cura um, suavizar com carinhos maternais e palavras feitas de bondade os tormentos que torturam o outro. Ao moribundo - apontam os amplos braços de Cristo abertos na cruz para recebê-los e aos que voltam à vida - mostram o Lázaro ressurgindo para os trabalhos da existência".

O irmão provedor informou que já entrou em contato com o bispo diocesano e com a Superiora Geral das irmas de São Vicente de Paula, domiciliada em Paris. Após a construção do prédio destinado ds irmas de caridade, edificado ao longo da capela de Nosso Senhor dos Passos, firmou-se o contrato a $30.7 .1891 \mathrm{com}$ as irmas Vicentinas, que passaram a trabalhar na Santa Casa.

As recolhidas da Casa da Roda viviam isoladas, era expressamente proibida qualquer comunicação com o mundo exterior, as visitas seriam sempre em presença da regente.

$\mathrm{O}$ regimento da Casa dos Expostos orientava sobre preenchimento de guias, compra de gênero, seleçao de empregados, tipos de cama, livros de registros, mas silenciava sobre o afeto ou tratamento carinhoso aos enjeitados, possivelmente por causa do sistema de contrataçao de criadeiras e amasde-leite.

A pesquisa ainda está em fase de levantamento de dados para a elaboração das fichas mestras, que depois serão desdobradas em outras fichas, de acordo com a cor, idade, sexo, data de colocação na Roda, batismo, padrinho, madrinha, criadeira, local de criação, doenças, grau de instrução, pecúlio, adoção, casamento e óbito dos expostos. 


\section{FONTES CONSULTADAS}

Livros de Matrícula no 1, de 29.1.1838 a 20.7.1857

Livros de Matrícula no 2, de 24.1.1857 a 16.1.1875

Livros de Matrícula no 3, de 18.1.1875 a 27.9.1891

Livros de Registro no 1, de 7.1.1843 a 4.6.1845

Livros de Registro no 2, de 18.6.1845 a 30.12.1847

Livros de Registro n? 3, de 11.1.1848 a 25.10.1851

Livros de Registro no 4, de 1.11.1851 a 26.5.1860

Livros de Registro n? 5, de 31.5 .1860 a 16.10 .1868

Livros de Registro no 6, de 22.10.1868 a 4.4 .1870

Livros de Registro no 7, de 22.10.1868 a 6.11.1877

Livros de Registro no 8, de 1.2 .1870 a 3.10 .1874

Livros de Registro n' 9, de 24.1.1878 a 9.11 .1883

Livros de Registro no 10, de 18.1 .1875 a 29.12 .1885

Livros de Registro n? 11, de 8.1.1886 a 4.2.1892

Livros de Registro no 12, de 19.2.1892 a 16.8.1904

Relatórios dos anos de 1858, 1864, 1868, 1884

Regimento da Casa dos Expostos da Santa Casa de Misericórdia, Porto Alegre, Tip. Isidoro José Lopes, 1842.

"Professor no Departamento de História da PUCRS. 


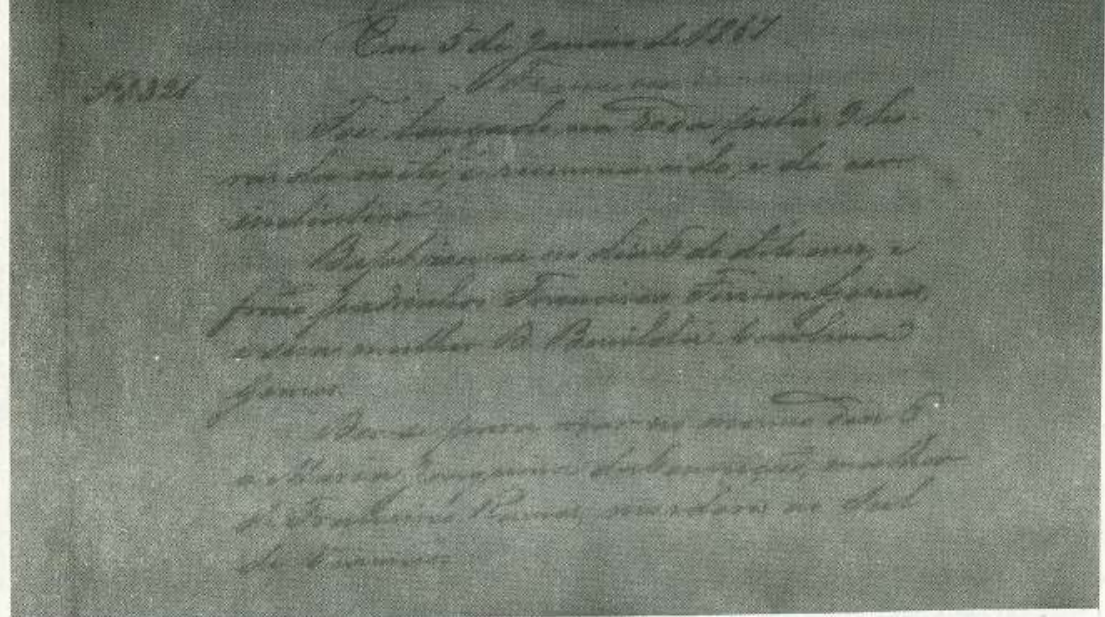

LIVRO DE REGISTRO DOS EXPOSTOS - SANTA CASA DE MISERICORDIA - 1967

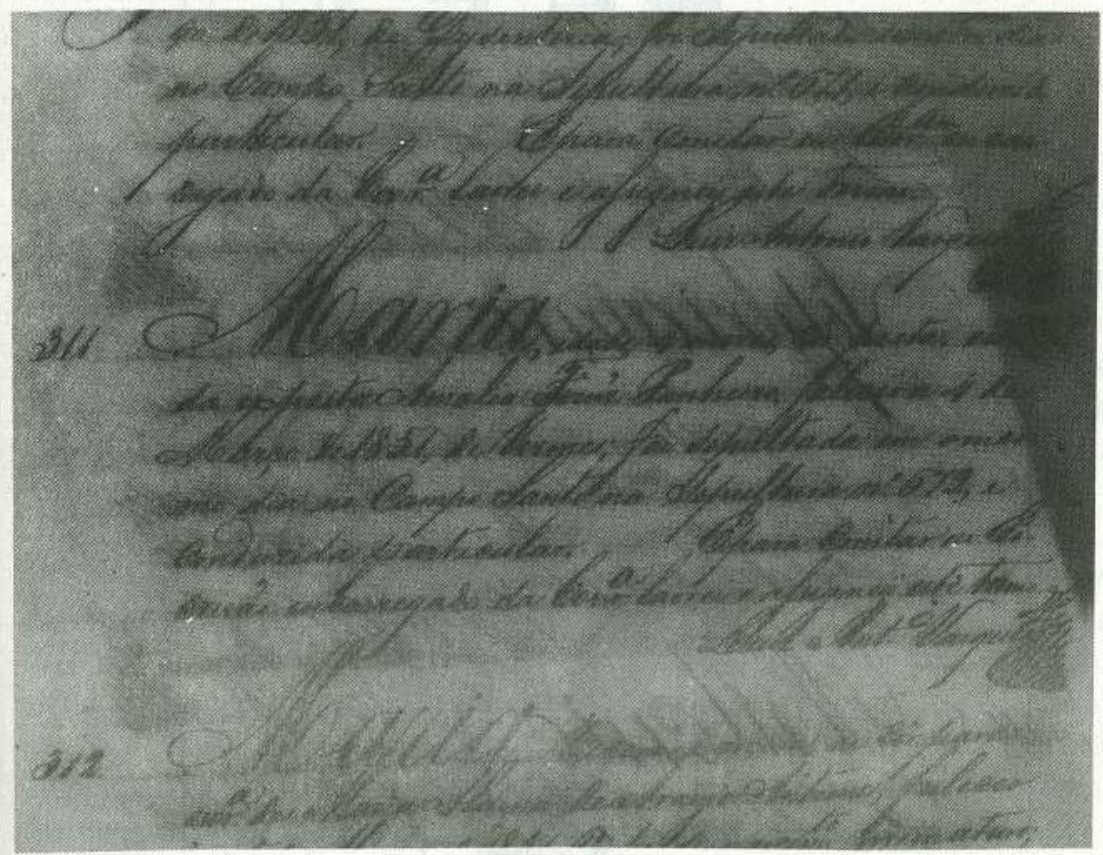

LIVRO DE OBITOS DOS ESCRAVOS - SANTA CASA DE MISERICORDIA - 1851 


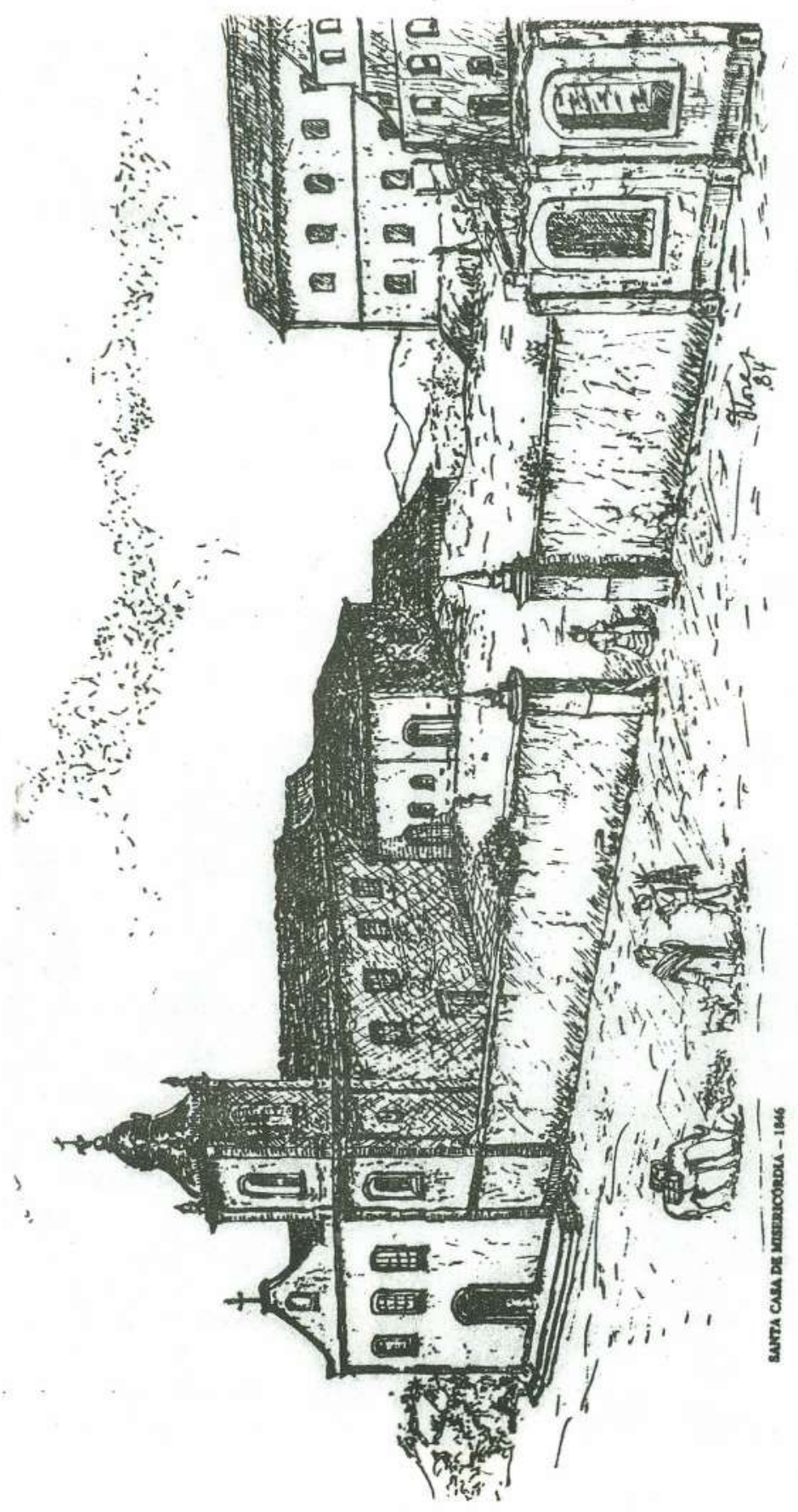

